\title{
Analysis on Variation Features of Concentration of Main Air Pollutants in Tangshan
}

\author{
Shi Youyu, ", Zhou Quan², Cao Xiaoxia ${ }^{1}$, Guo Zihan" ${ }^{1}$, Li Heng ${ }^{1}$ \\ ${ }^{1}$ Tangshan Meteorological Bureau, Tangshan, China \\ ${ }^{2}$ Luannan County Maternal and Child Health Hospital, Tangshan, China
}

\section{Email address:}

syy121@126.com (Shi Youyu), 543066138@qq.com (Zhou Quan), 419399800@qq.com (Cao Xiaoxia), tsqxjrsc@126.com (Guo Zihan), tsqxjrsc@126.com (Li Heng)

${ }^{*}$ Corresponding author

\section{To cite this article:}

Shi Youyu, Zhou Quan, Cao Xiaoxia, Guo Zihan, Li Heng. Analysis on Variation Features of Concentration of Main Air Pollutants in Tangshan. Science Discovery. Vol. 7, No. 4, 2019, pp. 214-219. doi: 10.11648/j.sd.20190704.17

Received: July 2, 2019; Accepted: August 6, 2019; Published: August 27, 2019

\begin{abstract}
The quality of air is closely related to the comprehensive competitiveness of a city. Analyzing and discussing the changing rules of various air pollutants and finding out the leading factors affecting the current environmental quality are of great significance for further improving the urban environment and formulating reasonable and economic environmental protection measures. Based on the daily concentrations monitoring data of six major air pollutant $\left(\mathrm{PM}_{2.5}, \mathrm{PM}_{10}, \mathrm{SO}_{2}, \mathrm{NO}_{2}, \mathrm{CO}_{\text {and }} \mathrm{O}_{3}\right)$ at six monitoring sites of Tangshan urban from 2015 to 2017, the characteristics of the concentration changes of six major air pollutants in Tangshan with time and space were analyzed by statistical analysis. The results showed that the ratio of air quality standard days increased year by year from 2015 to 2017 in Tangshan. The average concentration of $\mathrm{SO}_{2}$ was lower than the second standard in the Environmental Air Quality Standard, the average concentration of $\mathrm{NO}_{2}, \mathrm{PM}_{10}$ and $\mathrm{PM}_{2.5}$ was higher than the second standard in the Environmental Air Quality Standard; the Over-standard rate range of the average concentration of $\mathrm{NO}_{2}$ was the highest, ranging from $64 \%$ to $93 \%$, that of $\mathrm{SO}_{2}$ was the lowest, ranging from $0 \%$ to $3 \%$; The days of $\mathrm{PM}_{2.5}$ as the main pollutant were the most, ranging from 102 to 217 days, and the days of $\mathrm{SO}_{2}$ as the primary pollutant were the least, ranging from 0 to 3 days; the concentrations of $\mathrm{SO}_{2}, \mathrm{NO}_{2}, \mathrm{PM}_{10}, \mathrm{PM}_{2.5}$ and $\mathrm{CO}$ were the highest in winter and $\mathrm{O}_{3}$ in summer.
\end{abstract}

Keywords: Tangshan, Pollution Concentration, Over-standard Rate

\section{唐山市主要大气污染物浓度变化特征分析}

\author{
史有瑜 ${ }^{*}$, 周权 ${ }^{2}$, 曹晓霞 ${ }^{1}$, 郭子晗 ${ }^{1}$, 李衡 ${ }^{1}$ \\ 1唐山市气象局, 唐山, 中国 \\ 㴒南县妇幼保健院, 唐山, 中国
}

\section{邮箱}

syy121@126.com（史有瑜），543066138@qq.com（周权），419399800@qq.com（曹晓霞），tsqxjrsc@126.com（郭子晗）， tsqxjrsc@126.com (李衡)

摘要: 空气质量的优劣与一个城市的综合竞争力密切相关, 分析和探讨各种大气污染物的变化规律, 找出影响当前环
境质量的主导因素, 对进一步改善城市环境, 制定合理、经济的环保措施具有重要意义。利用 $2015-2017$ 年唐山市区 6
个大气环境质量监测点位六种主要大气污染物 $\left(\mathrm{PM}_{2.5} 、 \mathrm{PM}_{10} 、 \mathrm{SO}_{2} 、 \mathrm{NO}_{2} 、 \mathrm{CO} \mathrm{O}_{3}\right)$ 浓度的逐日监测资料, 采取统计分
析方法, 对唐山市大气污染物浓度随时间、空间的变化特征进行分析。结果表明: 2015-2017年, 唐山空气质量达标天
数比率逐年增加; $\mathrm{SO}_{2}$ 年均浓度低于《环境空气质量标准》中二级标准, $\mathrm{NO}_{2} 、 \mathrm{PM}_{10}$ 和 $\mathrm{PM}$ 年均浓度高于《环境空气
质量标准》中二级标准; $\mathrm{NO}_{2}$ 日均值浓度范围超标率最大, 为 $64 \% \sim 93 \%, \mathrm{SO}_{2}$ 日均值浓度超标率最小, 为 $0 \sim 3 \%$ ～以 
$\mathrm{PM}_{2.5}$ 为首要污染物的天数最多, 为 $102 \sim 217$ 天, 以 $\mathrm{SO}_{2}$ 为首要污染物的天数最少, 为 $0 \sim 3$ 天; $\mathrm{SO}_{2} 、 \mathrm{NO}_{2} 、 \mathrm{PM}_{10} 、 \mathrm{PM}_{2.5}$ 和 $\mathrm{CO}$ 污染浓度冬季最大, $\mathrm{O}_{3}$ 污染浓度夏季最大。

关键词: 唐山, 污染浓度, 超标率

\section{1. 引言}

随着城市快速发展, 大气环境问题日益突出。空气质 量的优劣对投资环境和居民健康会造成直接影响, 因而越 来越受到政府和公众的关注[1]。距离北京150公里的唐山 是中国重要的老工业城市之一, 其传统产业包括煤炭、钢 铁和陶瓷。随着生态文明建设不断推进, 唐山以前所未有 的力度治理污染, 正努力建成东北亚地区经济合作窗口城 市、环渤海地区新型工业化基地、首都经济圈重要支点。

目前研究人员对唐山大气污染开展了一些研究, 周洪 霞等[2-3]研究了唐山市大气污染对居民呼吸系统疾病、心 血管疾病日门诊人数的影响, 白振宇等 [4]从唐山市大气环 境质量和排放现状出发,分析了大气污染物防治存在的问 题, 周瑞等[5]研究了唐山工业新区冬季采暖期大气污染变 化特征, 王晓元等[6]对夏秋季节唐山市大气污染状况进行 了分析, 高红霞等[7-9]对唐山市工业区大气污染对小学生 肺功能、小学生生长发育、儿童健康的影响进行了研究, 誉静娟等 [10]探讨了唐山市的能耗结构和功能区分布与当 时大气污染状况的关系。张晓郁等[11]利用ArcGIS对 2014 年空气自动监测站数据分析, 发现北部山区、市中心区附
近区域空气质量波动较大, 郑艳萍 [12] 对唐山市2004 2011年空气污染物进行分析, 发现唐山市首要污染物主要 是 $\mathrm{PM}_{10}$, 其次是 $\mathrm{SO}_{2}$ 。

唐山市随着经济转型和环境治理, 近几年环境质量情 况发生了较大的变化。本文利用2015-2017年唐山市区6个 自动监测站 $\mathrm{PM}_{2.5} 、 \mathrm{PM}_{10} 、 \mathrm{SO}_{2} 、 \mathrm{NO}_{2} 、 \mathrm{CO} 、 \mathrm{O}_{3}$ 逐日数据资 料, 对近几年唐山市大气环境质量进行分析, 找出影响当 前环境质量的主导因素, 以便为进一步改善唐山空气质量 状况, 制定合理、经济的环保措施提供一定的参考依据。

\section{2. 监测点位分布}

唐山市区设有供销社、雷达站、物资局、十二中、陶 瓷公司和小山 6 个大气环境质量监测点位, 按照国家《环 境空气质量标准》（GB3095-2012）要求对城市环境空气 质量实施自动监测, 监测项目为二氧化硫 $\left(\mathrm{SO}_{2}\right)$ 、二氧 化氮 $\left(\mathrm{NO}_{2}\right)$ 、可吸入颗粒物 $\left(\mathrm{PM}_{10}\right)$ 、细颗粒物 $\left(\mathrm{PM}_{2.5}\right)$ 、 臭氧 $\left(\mathrm{O}_{3}\right)$ 和一氧化碳 $(\mathrm{CO})$ 。唐山市区大气环境质量 监测点位见图1。

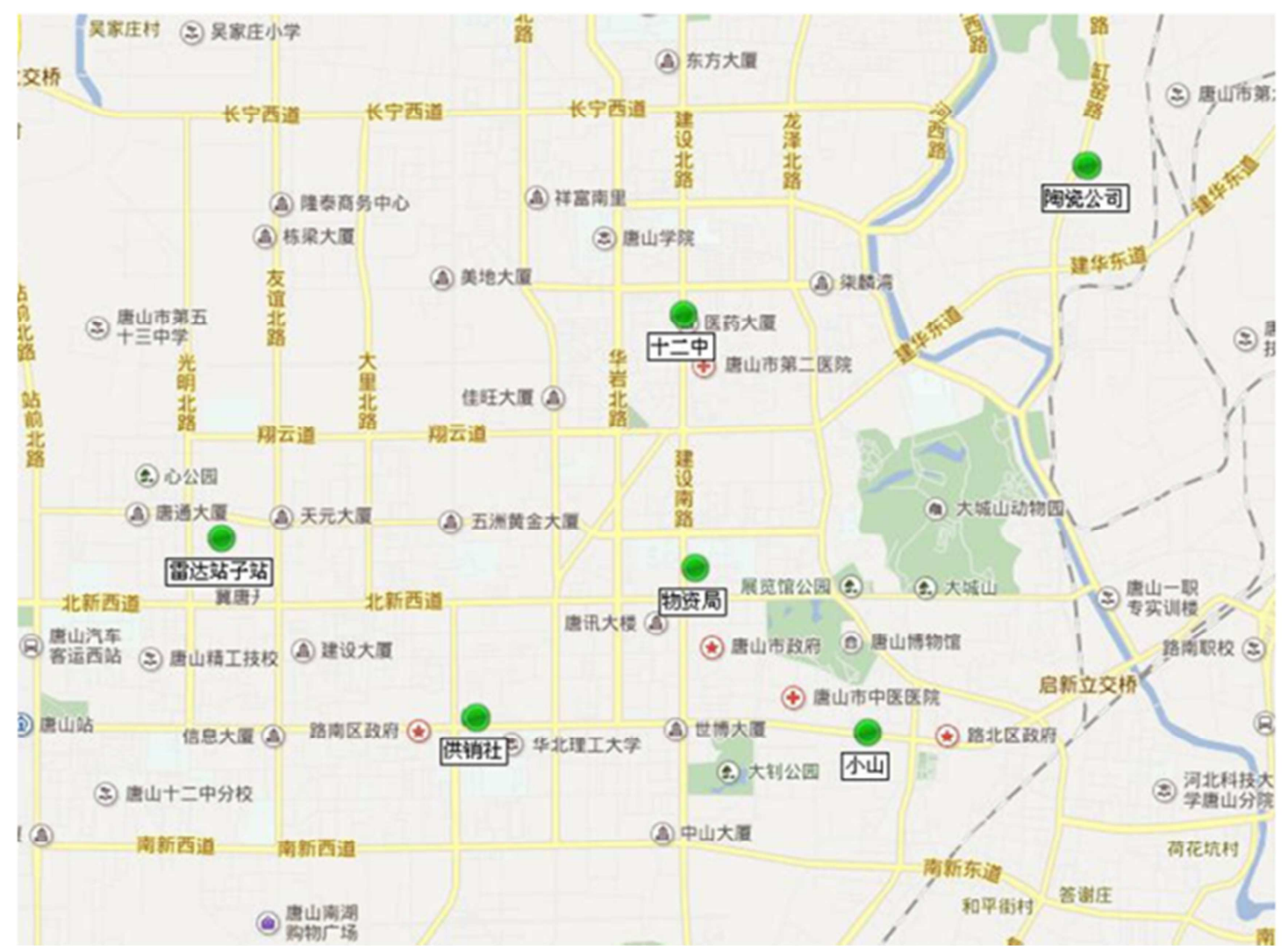

图1 唐山市区大气环境质量监测点位图。 


\section{3. 研究资料与研究方法}

\section{1. 研究资料}

所有资料取自唐山市气象信息共享平台，时间序列为 2015年1月 1日-2017年12月31日，环境气象资料包括供销 社、雷达站、物资局、十二中、陶瓷公司、小山的 $\mathrm{PM}_{2.5}$ 、 $\mathrm{PM}_{10} 、 \mathrm{SO}_{2} 、 \mathrm{NO}_{2} 、 \mathrm{CO} 、 \mathrm{O}_{3}$ 污染物环境气象日数据。

\section{2. 研究方法}

运用统计学方法分析大气污染物的变化特征, 运用 Excel2007软件进行作图。

\section{4. 结果与分析}

\section{1. 大气污染物浓度总体情况}

对6个监测站污染物浓度取平均值, 按照AQI指数等 级划分, 统计得出2015-2017年大气环境状况如表1所示。 可见, 近年唐山达标天数比率呈逐年增加趋势, 说明环境 污染治理措施已见成效。但是空气质量为优的天数还较少, 尤其2017年仅为个位数, 也表明环境治理还任重道远。

表1 2015-2017年唐山市大气环境状况。

\begin{tabular}{|c|c|c|c|c|c|c|c|c|}
\hline 年份 & 统计天数 & 优 & 良 & 轻度污染 & 中度污染 & 重度污染 & 严重污染 & 达标率 \\
\hline 2015 & 360 & 15 & 141 & 105 & 59 & 32 & 8 & 0.433 \\
\hline 2016 & 366 & 18 & 182 & 103 & 26 & 28 & 9 & 0.546 \\
\hline 2017 & 362 & 6 & 199 & 89 & 38 & 25 & 5 & 0.566 \\
\hline
\end{tabular}

表2为唐山市2015-2017年大气污染物年平均浓度值。 可以看出, $\mathrm{SO}_{2} 、 \mathrm{PM}_{2.5} 、 \mathrm{PM}_{10}$ 年均浓度在逐年递减, 说明 国家新政实施后，大气中的 $\mathrm{SO}_{2}$ 得到了有效的控制。虽然 $\mathrm{PM}_{2.5} 、 \mathrm{PM}_{10}$ 年均浓度呈递减趋势, 但仍超出国家标准很 多，2017年 $\mathrm{PM}_{2.5}$ 年均浓度超过国家标准 $88.6 \%, \mathrm{PM}_{10}$ 年均 浓度超过国家标准 $70.0 \%$, 故有必要进一步加强 GB1327-2014[13]在各行业的实施。同时, 减少高硫燃料 在锅炉中的比重, 以及各行业污染物高效回收形成完善的 循环链, 也能较好地缓解大气污染的压力。

表2 2015-2017年唐山市大气污染物年均浓度值 单位: $\mathrm{mg} / \mathrm{m}^{-3}$ 。

\begin{tabular}{lllllll}
\hline 年份 & $\mathbf{S O}_{2}$ & $\mathbf{N O}_{2}$ & $\mathbf{P M}_{2.5}$ & $\mathbf{P M}_{\mathbf{1 0}}$ & $\mathbf{C O}$ & $\mathbf{O}_{\mathbf{3}}$ \\
\hline 2015 & 0.049 & 0.061 & 0.085 & 0.141 & 2.1 & 0.093 \\
2016 & 0.046 & 0.058 & 0.074 & 0.127 & 2.3 & 0.094 \\
2017 & 0.040 & 0.059 & 0.066 & 0.119 & 2.0 & 0.104 \\
\hline
\end{tabular}

\section{2. 监测点大气污染物浓度分析}

(1) 二氧化硫 $\left(\mathrm{SO}_{2}\right)$

唐山市区6个监测点2015 2017年 $\mathrm{SO}_{2}$ 年均浓度值在 0.032 0.055 mg $/ \mathrm{m}^{3}$ 之间, 低于《环境空气质量标准》中二 级标准 $\left(0.060 \mathrm{mg} / \mathrm{m}^{3}\right)$ 。日均值浓度范围在 $0.003 \sim 0.222 \mathrm{mg} /$ $\mathrm{m}^{3}$ 之间, 超标率在 $0 \sim 3 \%$ 之间, 2015年各监测点均有超标, 小山监测点超标最多, 超标率达到 $3 \%$, 其次为供销社监测 点, 二者均位于唐山市南部区域; 2016年雷达站和供销社 监测点全年均达标, 其余四个监测点超标; 2017年仅十二 中监测点略有超标, 其余监测点全年均达标。

\section{(2) 二氧化氮 $\left(\mathrm{NO}_{2}\right)$}

唐山市区6个监测点2015～2017年二氧化氮 $\left(\mathrm{NO}_{2}\right)$ 年均浓度值在 $0.047 \sim 0.066 \mathrm{mg} / \mathrm{m}^{3}$ 之间, 高于《环境空气质 量标准》中二级标准 $\left(0.040 \mathrm{mg} / \mathrm{m}^{3}\right)$ 。日均值浓度范围在 $0.007 \sim 0.196 \mathrm{mg} / \mathrm{m}^{3}$ 之间, 整体超标率较高, 超标率 2015 年为 $71 \% \sim 90 \% ， 2016$ 年略低，为 $64 \% \sim 87 \% ， 2017$ 年最 高, 为 $72 \% \sim 93 \%$ 。物资局监测点 $\mathrm{NO}_{2}$ 浓度超标率最低, 小山监测点超标率最高。

(3) 可吸入颗粒物 $\left(\mathrm{PM}_{10}\right)$
唐山市区6个监测点 $2015 \sim 2017$ 年可吸入颗粒物 $\left(\mathrm{PM}_{10}\right)$ 年均浓度值在 $0.107 \sim 0.150 \mathrm{mg} / \mathrm{m}^{3}$ 之间, 高于 《环 境空气质量标准》中二级标准 $\left(0.070 \mathrm{mg} / \mathrm{m}^{3}\right)$ 。日均值浓度 范围在 $0.003 \sim 0.844 \mathrm{mg} / \mathrm{m}^{3}$ 之间，超标率在 $16 \% \sim 44 \%$ 之间， 2015年超标率最高, 2016年次之, 2017年最低。六个监测 点中, 供销社监测点超标率最低, 陶瓷公司监测点超标率 最高。

(4) 细颗粒物 $\left(\mathrm{PM}_{2.5}\right)$

唐山市区6个监测点2015 2017年细颗粒物 $\left(\mathrm{PM}_{2.5}\right)$ 年均浓度值在 $0.061 \sim 0.089 \mathrm{mg} / \mathrm{m}^{3}$ 之间, 高于《环境空气质 量标准》中二级标准 $\left(0.035 \mathrm{mg} / \mathrm{m}^{3}\right)$ 。日均值浓度范围在 $0.003 \sim 0.391 \mathrm{mg} / \mathrm{m}^{3}$ 之间，超标率在 $24 \% \sim 51 \%$ 之间， 2015 年超标率最高, 2016年次之, 2017年最低。六个监测点中, 供销社监测点超标率最低, 十二中监测点超标率最高。

(5) 臭氧 $\left(\mathrm{O}_{3}\right)$

唐山市区6个监测点2015 2017年臭氧 $\left(\mathrm{O}_{3}\right)$ 日最大 8 小时年均浓度值在 $0.093 \sim 0.104 \mathrm{mg} / \mathrm{m}^{3}$ 之间。日均值浓度范 围在0 0.313 mg $/ \mathrm{m}^{3}$ 之间, 超标率在 $18 \sim 23 \%$ 之间。六个 监测点中, 十二中监测点超标率最低, 供销社监测点超标 率最高。

\section{（6）一氧化碳（CO）}

唐山市区各监测点2015～2017年一氧化碳（CO）年 均浓度值在 $1.8 \sim 2.5 \mathrm{mg} / \mathrm{m}^{3}$ 之间。日均值浓度范围在 $0.2 \sim$ $19.0 \mathrm{mg} / \mathrm{m}^{3}$ 之间, 超标率在 $4 \% \sim 9 \%$ 之间, 各年各监测点超 标率相差不大。

\section{3. 污染物浓度时间变化特征}

图2为2015-2017年唐山市六种大气污染物逐月浓度 贡献率。由图可见, $\mathrm{SO}_{2} 、 \mathrm{NO}_{2} 、 \mathrm{PM}_{10} 、 \mathrm{PM}_{2.5}$ 三年平均浓 度具有相似的月变化特征, 均为最大值出现在冬季的 12 月和 1 月, 最小值出现在夏季的7月和 8 月; $\mathrm{CO}$ 三年平均浓 度最大值也出现在冬季的 12 月, 但最小值出现在春季的 5 月份; $\mathrm{O}_{3}$ 三年平均浓度与其它污染物不同, 其最大值出现 在夏季的 6 月, 最小值出现在冬季的 12 月 $(3 \%)$ 。究其原 
因, 夏季较高的气温和辐射强度加速了大气中氧分子的分 解, $\mathrm{O}_{3}$ 的生成速度大于其分解速度, 从而使 $\mathrm{O}_{3}$ 含量升高, 所以臭氧在夏季浓度高, 冬季浓度低。

另外, 就季节分布而言, $\mathrm{SO}_{2} 、 \mathrm{PM}_{10} 、 \mathrm{PM}_{2.5}$ 浓度均为 冬季 $>$ 春季 $>$ 秋季 $>$ 夏季, 说明冬季取暖和化石燃料的使
用对 $\mathrm{SO}_{2} 、 \mathrm{PM}_{10} 、 \mathrm{PM}_{2.5}$ 浓度造成较大影响, 冬季风速较小 也不利于污染物的扩散。 $\mathrm{NO}_{2}$ 浓度为冬季 $>$ 秋季 $>$ 春季 $>$ 夏季, $\mathrm{CO}$ 浓度为冬季 $>$ 秋季 $>$ 夏季 $>$ 春季, 说明冬季对 $\mathrm{NO}_{2}$ 和 $\mathrm{CO}$ 污染物影响也较大。 $\mathrm{O}_{3}$ 浓度为夏季 $>$ 春季 $>$ 秋季 $>$ 冬季, 这是由于夏季温度较高, 更易形成 $\mathrm{O}_{3}$ 污染物。

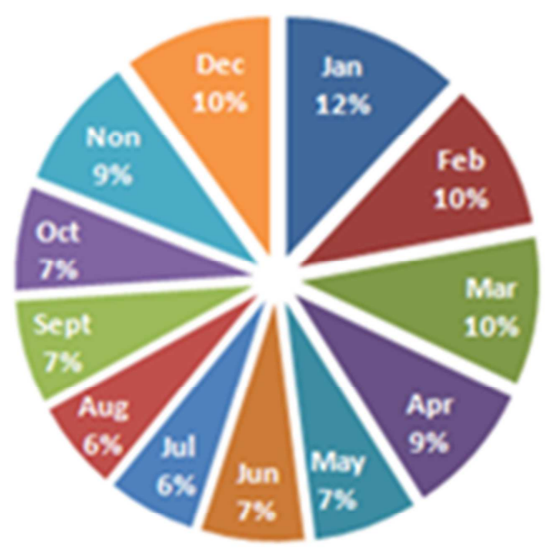

(a) $\mathrm{SO}_{2}$

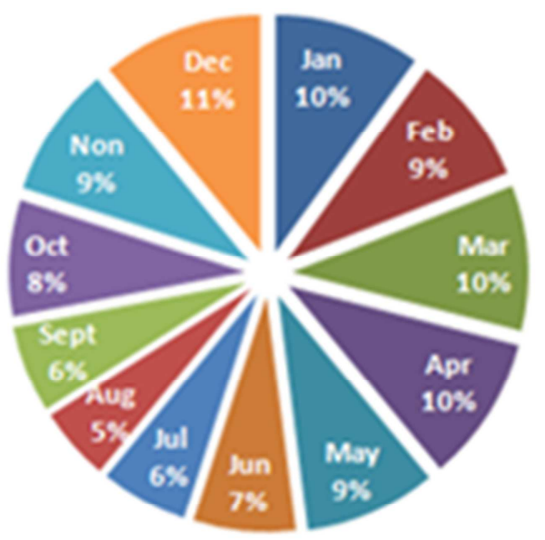

(c) $\mathrm{PM}_{10}$

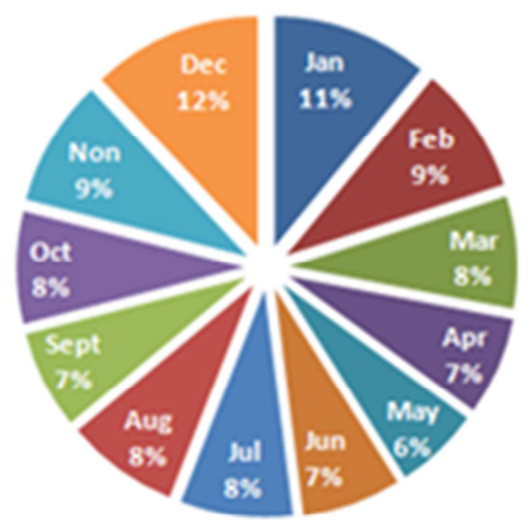

(e) $\mathrm{CO}$

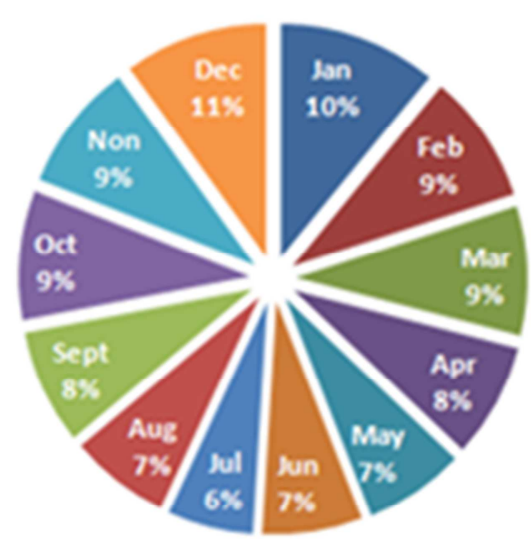

(b) $\mathrm{NO}_{2}$

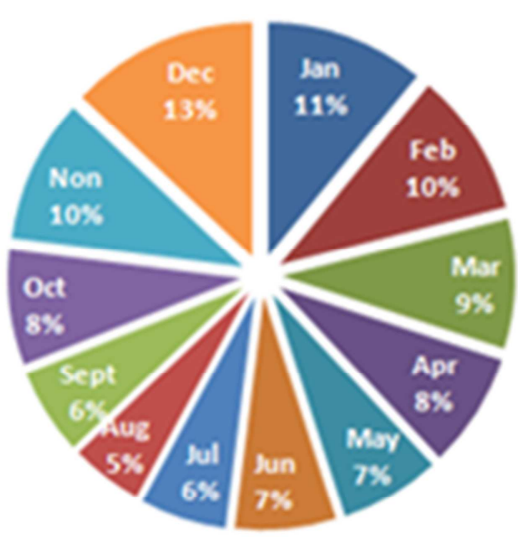

(d) $\mathrm{PM}_{2.5}$

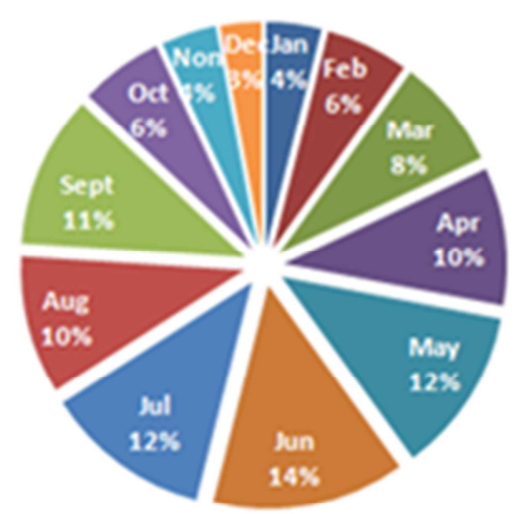

(f) $\mathrm{O}_{3}$

图2 2015-2017年唐山市六种大气污染物逐月浓度贡献率。 


\section{4. 首要污染物分析}

(1) 二氧化硫 $\left(\mathrm{SO}_{2}\right)$

2015 2017年以SO2为首要污染物的天数较少，2015 年陶瓷公司监测站未出现以 $\mathrm{SO} 2$ 为首要污染物的天数, 其 余 5 个监测站也仅有 $1 \sim 3$ 天以 $\mathrm{SO} 2$ 为首要污染物; 2016年 仅十二中监测站出现 1 天以 $\mathrm{SO} 2$ 为首要污染物, 其余监测 站均未出现； 2017 年仅雷达站监测站出现 1 天以 $\mathrm{SO} 2$ 为首 要污染物, 其余监测站均未出现。

\section{(2) 二氧化氮 $\left(\mathrm{NO}_{2}\right)$}

以 $\mathrm{NO}_{2}$ 为首要污染物的天数 2015 年各监测点平均为 43 天, 物资局监测点最少, 为 16 天, 陶瓷公司监测点最多, 为66天; 2016 年平均为 58 天, 物资局监测点最少, 为 8 天, 供销社监测点最多, 为86天; 2017 年平均为 73 天, 陶瓷公 司监测点最少, 为 17 天, 供销社监测点最多, 为 117 天。

\section{(3) 可吸入颗粒物 $\left(\mathrm{PM}_{10}\right)$}

以 $\mathrm{PM}_{10}$ 为首要污染物的天数 2015 年各监测点平均为 70 天, 小山监测点最少, 为 45 天, 物资局监测点最多, 为 96 天； 2016 年平均为 80 天, 雷达站监测点最少, 为 58 天, 物资局监测点最多，为147天；2017年平均为88天，雷达 站监测点最少, 为 43 天, 陶瓷公司监测点最多, 为 157 天。

\section{(4) 细颗粒物 $\left(\mathrm{PM}_{25}\right)$}

以 $\mathrm{PM}_{2.5}$ 为首要污染物的天数 2015 年各监测点平均为 194天, 陶瓷公司监测点最少, 为 175 天, 小山监测点最多, 为 217 天; 2016 年平均为 139 天, 物资局监测点最少, 为 128 天, 十二中监测点最多, 为 165 天； 2017 年平均为 112 天, 供销社监测点最少, 为 102 天, 十二中监测点最多, 为 127 天。

\section{(5) 臭氧 $\left(\mathrm{O}_{3}\right)$}

以 $\mathrm{O}_{3}$ 为首要污染物的天数 2015 年各监测点平均为 37 天, 十二中监测点最少, 为 30 天, 雷达站监测点最多, 为 45 天； 2016 年平均为 51 天，物资局监测点最少，为 32 天, 小山监测点最多, 为64天; 2017 年平均为92天, 十二中监 测点最少, 为 84 天, 小山监测点最多, 为96天。

\section{（6）一氧化碳（CO）}

以 $\mathrm{CO}$ 为首要污染物的天数 2015 年各监测点平均为 4 天, 陶瓷公司、供销社、小山监测点相同, 均为 2 天, 物 资局监测点最多, 为 11 天； 2016年平均为 13 天，供销社监 测点最少, 为4天, 物资局监测点最多, 为 28 天；2017年 平均为 4 天, 供销社和小山监测点最少, 均为 1 天, 物资局 监测点最多, 为 11 天。

\section{5. 结论}

（1）2015-2017年，唐山空气质量达标天数比率呈逐 年增加趋势。

(2) 二氧化硫 $\left(\mathrm{SO}_{2}\right)$ 年均浓度值在 $0.032 \sim$ $0.055 \mathrm{mg} / \mathrm{m}^{3}$ 之间, 低于《环境空气质量标准》中二级标准。 日均值浓度超标率在0 3\%之间, 整体超标较少。

(3) 二氧化氮 $\left(\mathrm{NO}_{2}\right)$ 年均浓度值在 $0.047 \sim$ $0.066 \mathrm{mg} / \mathrm{m}^{3}$ 之间, 高于《环境空气质量标准》中二级标准。 日均值浓度超标率在 $64 \% \sim 93 \%$ 之间, 整体超标率较高。 物资局监测点超标率最低, 小山监测点超标率最高。
(4) 可吸入颗粒物 $\left(\mathrm{PM}_{10}\right)$ 年均浓度值在 0.107 $0.150 \mathrm{mg} / \mathrm{m}^{3}$ 之间, 高于《环境空气质量标准》中二级标准。 日均值浓度超标率在 $16 \%$ 44\%之间。供销社监测点超标 率最低, 陶瓷公司监测点超标率最高。

( 5 ) 细颗粒物 $\left(\mathrm{PM}_{2.5}\right)$ 年均浓度值在 $0.061 \sim$ $0.089 \mathrm{mg} / \mathrm{m}^{3}$ 之间, 高于《环境空气质量标准》中二级标准。 日均值浓度超标率在 $24 \% \sim 51 \%$ 之间。供销社监测点超标 率最低, 十二中监测点超标率最高。

(6) 臭氧 $\left(\mathrm{O}_{3}\right)$ 日最大 8 小时年均浓度值在 0.093 $0.104 \mathrm{mg} / \mathrm{m}^{3}$ 之间。日均值浓度超标率在 $18 \% \sim 23 \%$ 之间。 十二中监测点超标率最低, 供销社监测点超标率最高。

（7）一氧化碳（CO）年均浓度值在 $1.8 \sim 2.5 \mathrm{mg} / \mathrm{m}^{3}$ 之间。日均值浓度超标率在 $4 \% \sim 9 \%$ 之间, 各年各监测点 超标率相差不大。

(8) 2015-2017年, 各监测点以 $\mathrm{PM}_{2.5}$ 为首要污染物的 天数最多, 为 $102 \sim 217$ 天, 以 $\mathrm{SO}_{2}$ 为首要污染物的天数最 少, 为 $0 \sim 3$ 天。这与郑艳萍的研究结论有所差别。

(9) $\mathrm{SO}_{2} 、 \mathrm{PM}_{10} 、 \mathrm{PM}_{2.5}$ 浓度冬季 $>$ 春季 $>$ 秋季 $>$ 夏 季, $\mathrm{NO}_{2}$ 浓度冬季 $>$ 秋季 $>$ 春季 $>$ 夏季, $\mathrm{CO}$ 浓度冬季 $>$ 秋 季 $>$ 夏季 $>$ 春季, $\mathrm{O}_{3}$ 浓度夏季 $>$ 春季 $>$ 秋季 $>$ 冬季。冬季 燃煤或化石燃料的使用加大了 $\mathrm{SO}_{2} 、 \mathrm{NO}_{2} 、 \mathrm{PM}_{10} 、 \mathrm{PM}_{2.5}$ 和 $\mathrm{CO}$ 的污染浓度, 夏季较高温度加大了 $\mathrm{O}_{3}$ 污染浓度。为了 减少环境污染, 建议继续加强城区绿化, 增加清洁能源的 使用, 减少化石燃料的使用, 优化工业生产工艺, 减少、 净化排放的废气。

\section{致谢}

本文为国家重点实验室开放课题项目（2017-KF-20）、 河北省气象局科研开发项目 (18ky26) 的阶段性成果之一。

\section{参考文献}

[1] 姚从容,陈鬼. 城市环境空气质量变化规律及污染特征分析 [J].干旱区资源与环境,2007(5):50-52。

[2] 周洪霞,魏刚,张田,等.唐山市大气污染与某医院呼吸系统疾 病日门诊人数的关系 [J]. 中国煤炭工业医学杂 志,2017,20(4):458-461。

[3] 周洪霞,蒋守芳,郭忠,等.唐山市大气污染对居民心血管疾病 日门诊和日住院人数的影响 [J]. 现代预防医 学,2015,42(12):2138-2141。

[4] 白振宇,王睿,王蓓,等.唐山市大气污染现状及防治对策 [J]. 绿色科技,2015(8):258-259。

[5] 周瑞,辛金元,邢立亭,等.唐山工业新区冬季采暖期大气污染 变化特征研究[J].环境科学,2011,32(7):1874-1880。

[6] 王晓元,辛金元,王跃思,等.唐山夏秋季大气质量观测与分析 [J].环境科学,2010,31(4):877-885。

[7] 高红霞,冯福民,张志坤,等.唐山市工业区大气污染对小学生 肺功能的影响[J].环境污染与防治,2001(6):323-325。 
[8] 高红霞,冯福民,张志坤.唐山市工业区大气污染对小学生生 长发育的影响[J].中国学校卫生,2001(2):124-125。

[9] 高红霞,冯福民,张志坤,等.唐山市工业区大气污染对儿童健 康影响的研究 [J].环境与健康杂志,2000(6):349-350+354。

[10] 兴静娟,曲修霞.唐山市城区结构与大气污染浅析 $[\mathrm{J}]$.地理学 与国土研究,1990(4):45-50。
[11] 张晓郁,晏淑梅,田茜. 基于GIS的唐山地区大气污染物时空 分布研究[J].中国环境监测,2017,33(3):49-55。

[12] 郑艳萍. 唐山市空气质量状况及污染物变化趋势分析:中国 气象学会.第29届中国气象学会年会论文集[C].沈阳:中国气 象学会,2012:4。

[13] 天津市环境保护科学研究院, 中国环境科学研究院.锅炉大 气污染物排放标准[S]. 北京: 中国标准出版社,2014。 